\title{
The research on upward influence tactics in organization under the Chinese cultural background
}

\author{
Yang Ying \\ International Business School \\ Yunnan University of Finance and Economics \\ Kunming, China \\ 11476423@qq.com
}

\author{
Chen Zhuo* \\ International Business School \\ Yunnan University of Finance and Economics \\ Kunming, China \\ 271602042@qq.com
}

\begin{abstract}
Research on the upward influence has become an important part of the field of enterprise management. It is because that the use and effects of upward influence are relating to superior-subordinate relationship as well as achieving individual and organizational goals. This article, through the method of factor analysis, combined with China's cultural background, put forward the upward influence tactics six factors structure in organization and analyzed the characteristics of the six kind of influence tactics use frequency.
\end{abstract}

Keywords-influence tactics; upward influence; use freque ncy

\section{INTRODUCTION}

Influence in the field of enterprise management, refers to persuade others to recognize their own ideas, follow their own actions, making others' attitude and behavior change [1]. The executor of influence is called influencer, and the object of influence is referred to as the target.

In organizations with hierarchy, the most important relationship is the relationship between the superiors and the subordinates. completing organizational tasks needs that superiors and subordinates cooperate with each other. As organizations increasingly flat hierarchy, the interaction between the superiors and subordinates is more and more frequent, therefore, subordinates have more opportunities and capabilities to influence superiors. Subordinates influencing their superior successfully make them contribute the wisdom and ability to their organizations, also make them full use of human resources, that improve the effectiveness of the organization operation, at the same time can improve the employee' s job performance and reduce staff turnover rate. Moreover, the subordinate only by influencing the superior, making superior to accept his advice, to play their own influence.

Kipnis put forward POIS-M scale with six strategies which are summarized as three categories: Hard strategy, Soft strategy and the Rationality strategy [2]. Later, Shilit and Locke use the method of summarizing literature to summed up upward influence tactics that are higher up in the past research strategy in nine categories[3]. Most of them appeared in the study of Kipnis, in addition Shilit and Locke raised two new tactics which are Adherence to Rules and Manipulation, so as

\footnotetext{
* Corresponding author
}

to further perfect POIS-M scale. In 1990, Schreisheim and Hinklin made a confirmatory factor analysis aimed at POIS-M scale. They deleted the factor loading lower factors, exhibited POIS-M simplified version with 18 tactics in 6 factors [4]. Schreisheim and Hinklin's scale has higher reliability and validity than POIS-M, and since then POIS-M scale and POIS-M simplified version scale become widely accepted classification of upward influence tactics. However, these research results are derived from western culture, which cannot be cross-cultural application, especially cannot be applicable to the Oriental culture [5]. As a result, Ralston's study, involving management staff in Hong Kong, China, France and other countries, developed a set of Strategies of Upward Influence (SUI) which contains 38 items of five dimensions. However, the research achievements of Ralston has not been widely recognized, perhaps because the test objects' average working time is short (1.9 years) in Hong Kong.

Study of upward influence tactics under the Chinese culture background started relatively late, research results relatively less. Taiwan scholar Li used the depth interview method to collect up influence tactics respectively for employees of the three nonprofit organizations respectively in Taiwan, which are then divided into 19 [6]. In the study of China mainland area, Huang adopt the way of combining individual interviews with open questionnaire investigation to gather data in more than 20 enterprises in Guangzhou, forming up the four factors influencing tactics structure in Chinese enterprises. The four factors are relationship, communication, compliance, and job performance [7]. The study of Li and Huang are investigated in a particular organization, therefore the results of these studies are not very good universality. As a result, the purpose of this paper is to study structure and dimension of upward influence tactics in organization under the Chinese culture background, and further explore how the uniqueness of Chinese culture affect upward influence tactics.

\section{FORM UPWARD INFLUENCE TACTICS QUESTIONNAIRE}

\section{A. The Design of the Questionnaire}

Based on collecting and summarizing relevant literature of the existing influence strategy and upward influence tactics, referencing the research questionnaire established and confirmed with better effect, analyzing the dimension and topic of these influence tactics, and combining with Chinese 
culture which focus on organization relationship as well as heavy human feelings characteristics, this article mainly according to Sun [8] compiled by scale, Fu [9] compiled by the scale and Ralston compiled by SUI scale, selects 32 items of the above literatures to form the questionnaire about the structure of the upward influence tactics in this paper.

\section{B. The Questionnaire for Measuring}

The questionnaire distributed objects follow the following principles: (1) Because this article is trying to find out the common types of upward influence tactics in the organization under the background of the Chinese culture, the sample scope is supposed to include state-owned enterprises, private enterprises, joint venture/sole proprietorship enterprise, government agencies and public institutions, but not only limited to the business enterprise inside. (2) In view of the upward influence tactics structure investigation, questionnaire distributed object for employees in the organization, and they are the users of upward influence tactics. Therefore, there are 60 available samples. They are all kinds of type organization members of the organization. Altogether 67 questionnaires are put out, and 60 are taken back. The effective returns-ratio is $89.55 \%$.

\section{The Revision of the Questionnaire}

This article compiled by <The Questionnaire on Upward Influence Tactics in Organization Under the Chinese Cultural Background $>$ in an objective statement required subjects evaluating the use frequency of various concrete upward influence tactics which implemented upon their superior, questionnaire using Likert five-point scale, including "1" as never used, " 5 " on behalf of the frequent use.

Survey data are analyzed by factor analysis with statistical software SPSS19, and then further revised the questionnaire. First with principal component analysis to extract factor, with the biggest variance rotation to rotate load matrix, according to the results of the factor analysis to revise questionnaire items, the concrete revision principle is: (1) the items with high factor loading, high factor common degree, no obvious cross dimension will be chosen. (2) Adjust the items with not clear semantics to create ambiguity. (3) Remove the items with low universality. After continuous correction, we formed upward influence tactics structure of this paper according to the selected items. We final identified 24 tactics items, and their KMO test value is 0.522 . It is generally believed that the greater KMO value said the more common factors between variables, which is more suitable for factor analysis. Collecting data is suitable for factor analysis if the KMO value is greater than 0.5. Bartlett ball inspection of data significantly (significant probability of $0.000<0.01$ ), indicating that is suitable for factor analysis. Revised upward influence tactics structure consists of six factors, total variance explained at a rate of $80.020 \%$ (table1 and table 2), which preliminary confirmed that the structure of the upward influence tactics in organization under the Chinese cultural background is multi-dimensional and six dimensions structure model.

TABLE I. TOTAL VARIANCE EXPLAINED OF UPWARD INFLUENCE TACTICS (SEE P. 3)

\begin{tabular}{|c|c|c|c|c|c|c|c|c|c|}
\hline & \multicolumn{3}{|c|}{ The initial eigenvalue } & \multicolumn{3}{|c|}{ Extraction of sum of squares } & \multicolumn{3}{|c|}{ Rotate the sum of squares } \\
\hline $\begin{array}{c}\text { Factor } \\
\quad \mathrm{s}\end{array}$ & Summation & $\begin{array}{c}\text { The variance } \\
\text { contribution } \\
\text { rate }\end{array}$ & $\begin{array}{c}\text { The cumulative } \\
\text { variance } \\
\text { contribution rate }\end{array}$ & Summation & $\begin{array}{c}\text { The variance } \\
\text { contribution } \\
\text { rate }\end{array}$ & $\begin{array}{c}\text { The } \\
\text { cumulative } \\
\text { variance } \\
\text { contribution } \\
\text { rate }\end{array}$ & Summation & $\begin{array}{c}\text { The variance } \\
\text { contribution rate }\end{array}$ & $\begin{array}{c}\text { The } \\
\text { cumulative } \\
\text { variance } \\
\text { contribution } \\
\text { rate }\end{array}$ \\
\hline 1 & 11.035 & 42.442 & 42.442 & 11.035 & 42.442 & 42.442 & 4.337 & 16.680 & 16.680 \\
\hline 2 & 3.422 & 13.163 & 55.605 & 3.422 & 13.163 & 55.605 & 3.856 & 14.831 & 31.511 \\
\hline 3 & 2.584 & 9.940 & 65.545 & 2.584 & 9.940 & 65.545 & 3.398 & 13.068 & 44.579 \\
\hline 4 & 1.513 & 5.818 & 71.362 & 1.513 & 5.818 & 71.362 & 3.363 & 12.934 & 57.513 \\
\hline 5 & 1.196 & 4.601 & 75.964 & 1.196 & 4.601 & 75.964 & 3.094 & 11.898 & 69.412 \\
\hline 6 & 1.055 & 4.056 & 80.020 & 1.055 & 4.056 & 80.020 & 2.758 & 10.608 & 80.020 \\
\hline
\end{tabular}

TABLE II. FACTOR STRUCtURE OF UPWARd INFLUENCE TACTICS(SEE P. 3)

\begin{tabular}{|c|c|c|c|c|c|c|c|}
\hline \multirow[t]{2}{*}{ Items } & \multicolumn{6}{|c|}{ Factors } & \multirow{2}{*}{$\begin{array}{c}\text { Factor } \\
\text { common } \\
\text { degrees }\end{array}$} \\
\hline & $F 1$ & $F 2$ & F3 & F4 & F5 & F6 & \\
\hline Q12 In order to achieve a goal, find boss many times repeat requests & 0.786 & & & & & & 0.692 \\
\hline Q18 Spread negative information about the boss to forces him/she promised & 0.854 & & & & & & 0.832 \\
\hline Q13 Do not speak of specific reasons, request directly to the boss & 0.631 & & & & & & 0.647 \\
\hline Q21 Suggest to the boss, I got the higher leadership recognition and support & 0.700 & & & & & & 0.860 \\
\hline $\begin{array}{l}\text { Q28 If the boss agreed to my requests, I can promise to help him/her to do } \\
\text { other things }\end{array}$ & 0.819 & & & & & & 0.819 \\
\hline
\end{tabular}


Table II, cont.

\begin{tabular}{|c|c|c|c|c|c|c|c|}
\hline $\begin{array}{l}\text { Q29 Refer to my previous help for him/her, hinted that he/she should promis } \\
\text { e me }\end{array}$ & 0.780 & & & & & & 0.807 \\
\hline Q6 Detailed explain my request/advice would bring to the company's benefits & & 0.690 & & & & & 0.710 \\
\hline Q7 Tell my superior my request/advice, ask him/her better solution & & 0.747 & & & & & 0.812 \\
\hline $\begin{array}{l}\text { Q8 discuss the feasibility of this request/advice with my superior, then appro } \\
\text { priate adjust it }\end{array}$ & & 0.771 & & & & & 0.919 \\
\hline Q10 Taking unpopular task, actively help supervisor to achieve work target & & 0.607 & & & & & 0.903 \\
\hline Q11 In daily work show my ability, let the boss appreciated & & 0.635 & & & & & 0.706 \\
\hline Q9 Complete every task assigned by the superior timely and effectively & & 0.581 & & & & & 0.765 \\
\hline Q22 give my boss a gift before Request/advice & & & 0.617 & & & & 0.790 \\
\hline $\begin{array}{l}\text { Q24 Try to participate in the boss's groups or activities, contact the supervis } \\
\text { or }\end{array}$ & & & 0.580 & & & & 0.845 \\
\hline Q25 Development the same interests and hobbies as my superior & & & 0.658 & & & & 0.761 \\
\hline Q31 affect boss through acquaintances In relation to the promotion. & & & 0.769 & & & & 0.868 \\
\hline Q27 Sincerely appreciate and praise the advantages of superior & & & & 0.786 & & & 0.890 \\
\hline $\begin{array}{l}\text { Q30 Praised the ability and performance of boss, to make him/her happy bef } \\
\text { ore request/advice }\end{array}$ & & & & 0.866 & & & 0.931 \\
\hline Q32 Maintain the image and interests of the superior in front of others. & & & & 0.637 & & & 0.780 \\
\hline $\begin{array}{l}\text { Q15 If my superior does not allow, I will directly show my displeasure or a } \\
\text { nger }\end{array}$ & & & & & 0.722 & & 0.698 \\
\hline Q17 Prompt superior he/she should agree according to company practices & & & & & 0.828 & & 0.826 \\
\hline Q20 Ask superior to find a higher leadership to deal with my requirements & & & & & 0.651 & & 0.802 \\
\hline Q4 Write request/advice into detailed application submitted to superior & & & & & & 0.680 & 0.821 \\
\hline Q5 Explain why the request/advice to the boss and the reasons & & & & & & 0.533 & 0.695 \\
\hline
\end{tabular}

\section{UPWARD INFLUENCE TACTICS STRUCTURE ANALYSIS IN} ORGANIZATION UNDER CHINESE CULTURAL BACKGROUND

In this article, through factor analysis, classified by the upward influence adopted by the organization members. Holding up the upward influence tactics type in the organization is very necessary, the organization managers could be establish training program pertinently, as well as members are able to enhance their own influence by selecting the appropriate influence tactics.

According to the result of table 2 , this study identified six kinds of upward influence tactics under the Chinese culture background:

Factor 1 contributes $16.680 \%$ of the variance, including 6 items, related to pressuring on the superior and talk about the conditions. The main content contains insisting, spreading negative information, suggesting that a higher level of support and talk about the conditions to the superior, etc. These tactics adopts negative means to pressure the superior, and if do not allow the subordinate's request, they will suffer negative effects, or damage the relationship between the superior and the subordinate.

Factor 2 contributes $14.831 \%$ of the variance, including 6 items, related to active and organization oriented consult as well as job performance. Main content is the organization interest, friendly request, negotiate improve the work performance, etc. These influence tactics involve mild persuasion strategy. The subordinate adopt these tactics trying to make the superior feel be respected, and his thoughts are very important to subordinates. At the same time the subordinate is trying to make opinion complement each other, so as to improve the success rate of upward influence.

Factor 3 contributes $13.068 \%$ of the variance, including four items, related to closing to the superior and enhancing the personal relationship. The main content contains gifts, informal close to superiors, obtaining the superior acquaintances support, etc. Using these strategies, subordinates attempt to establish personal relationships between themselves and superiors except working relationship, and strengthen the emotion or interest contact with superiors, so that superiors may agree with their ideas.

Factor 4 contributed $12.934 \%$ of the variance, including three items, related to praising and maintaining superiors. Subordinates adopt these items trying to show their support and loyalty for the superior, resulting the superior trusting them. In other words, it is to obtain the superior identity by improving the relationship between the superior and the subordinate.

Factor 5 contributed $11.898 \%$ of the variance, including three items, related to direct force. The content mainly includes expressing displeasure directly, executing organization regulations, appeal bypass the immediate leadership, etc. These strategies mainly adopt the method of tough, viciously. Subordinates adopt these strategies trying to direct promote 
superiors to agree with their ideas, and less care about the relationship quality between the subordinate and the superior. These items mainly used for work requests.

Factor 6 contributed $10.608 \%$ of the variance, including two items, related to rational persuasion, main content is to submit a written application and explain the reasons. Subordinates adopt these items trying to make the superior fully understand their ideas, express their fully thinking to the proposal.

Based on the use frequency analysis in six factors from all the samples (table 3), we can produce the following results:

\section{TABLE III. USE FREQUENCY IN SIX FACTORS OF UPWARD INFLUENCE TACTICS(SEE P. 4)}

\begin{tabular}{|c|c|}
\hline \multicolumn{1}{|c|}{ Items } & Average score \\
\hline F1 & 2.317 \\
\hline F2 & 3.825 \\
\hline F3 & 3.242 \\
\hline F4 & 3.484 \\
\hline F5 & 3.072 \\
\hline F6 & 3.592 \\
\hline
\end{tabular}

The highest-scoring tactics is the tactics related to active and organization oriented consults as well as job performance (3.825). Secondly, in turn, are the tactics associated with rational persuasion (3.592), the tactics associated with praise and maintaining superiors (3.484), the tactics related to closing to the superior and enhancing the personal relationship (3.242), and the tactics related to the direct force (3.072), the lowest-scoring tactics is related to pressuring on the superior and talk about the conditions (2.317). In other words, under the background of Chinese culture, the most commonly used upward influence tactics by organization members is the tactics with gentle persuasion, on the contrary, pressuring on the superior and talk about the conditions are the least.

\section{DISCUSS}

\section{A. The Use of Negative Strategies}

In the six categories of upward influence tactics that concluded by this article, two of them are types of negative tactics, which are direct force and pressure on the superior and talk about conditions. The table 3 shows that these two kinds of tactics are used in lowest frequency. One reason might be that, when subordinates use the two kinds of tactics, they will continue to do the things that superiors don't like to stimulate the superior, until their superiors agree to subordinates, and that is an offense to the superior. Using these strategies may make the superior give in, but may also damage the quality of the relationship between the superior and subordinate. Under the background of Chinese culture, the emphasis on the ways to influence someone that care for others' feelings and avoid embarrassing, but these tactics run counter to the Chinese traditional of kindness and pay attention to relationship, which makes these tactics the least frequently used. At the same time, the superior's approval may be out of coerced rather than a true approval for the idea. Therefore, in the process of the implementation, superior will show as not active.

\section{B. Relationship between the superior and the subordinate}

Through the analysis of the structure of upward influence tactics in organization, it can be seen that to establish and maintain the relationship between the superior and the subordinate are commonly used tactics under Chinese culture background, including the two tactics which are the praise and maintaining supervisor and increase of personal relationship. Under the Chinese culture, the "relationship" can be defined as a kind of informal, private special joint. Praising and maintaining the superior as an indirect way, which is used to trying to make superiors identify the subordinate, think that subordinates can be understand themselves. In this way, the distance between superiors and subordinates will be narrow. The subordinates' ultimate goal is also to establish and improve personal relation with superiors, so that they are able to influence superior decision by the emotional link.

\section{CONCLUSIONS}

This study analyzes upward influence tactics structure in the organization under the background of Chinese culture, through the questionnaire design, testing and questionnaire structure factor analysis process, and puts forward six factor structures that summarizes the basic upward influence tactics' types commonly used in organizations. These types reflect the organization members' characteristics in using upward influence tactics. The organization managers can train and guide organization members to play personal influences follow this structure, at the same time, the group members can selectively implement upward influence tactics referencing this article. Follow-up researchers to further study can focus on the difference in six kind of upward influence strategies utilization frequency under different situation factors, to provide more references for strategy implementation.

\section{ACKNOWLEDGMENT}

This work is the periodical result of the Yunnan Provincial Philosophy and Social Science Planning project named Research on the upward influence factors model and its application strategies in organization (No. YB2014109).

\section{REFERENCES}

[1] P.G. Zimbardo, and M.R. Leippe, "The Psychology of Attitude Change and Social Influence," Post and telecom Press, 2008.

[2] D. Kipnis, and S.M. Schmidt, "Upward Influence Styles: Relationship with Performance Evaluation," Salary and Stress. Administrative Science Quarterly, vol. 33, 1988, pp. 528-542.

[3] W.K. Schilit, and E.A. Locke, "A Study of Upward Influence in Organizations," Administrative Science Quarterly, vol. 27, 1982, pp. 304-316.

[4] C.A. Schriesheim, and T.R. Hinkin, "Influence tactics used by subordinates: A theoretical and empirical analysis and refinement of the Kipnis, Schmidt, and Wilkinson subscales," Journal of Applied Psychology, vol. 75, 1990, pp. 246-257.

[5] D.A. Ralston, D.J. Gustafson, R.H. Terpstra, and D.H. Holt, "Strategies of upward influence: A cross-national comparison of Hong Kong and American managers," Asia Pacific Journal of Management, vol. 10, 1993, pp. 157-175.

[6] S.Z. Li, and X.R. Chi, "Upward Influence Strategies in Organizations: Examining the Differences between Western and Chinese Upward Influence Models," Mass Communication Research, vol. 80, 2004, pp. 89-126. 
[7] B. Huang, "The Study on the Upward Influence Tactics of Chinese Staff and Influencing Factors of Tactics Evaluation," Dissertation, Jinan University, 2006.

[8] H.F. Sun, "The Structure of Influence Tactics of Management," Chinese Journal of Applied Psychology, vol. 4, 1998, pp. 3-9.

[9] P.P. Fu, and G. Yukl, "Perceived effectiveness of influence tactics in the united states and china," Leadership Quarterly, vol. 11, 2000, pp. 251-266. 